\title{
Increased p38-MAPK is responsible for chemotherapy resistance in human gastric cancer cells
}

Xianling Guo ${ }^{\dagger 1,2}$, Nannan $\mathrm{Ma}^{\dagger 1}$, Jin Wang ${ }^{3}$, Jianrui Song ${ }^{1}$, Xinxin $\mathrm{Bu}^{1}$, Yue Cheng1, Kai Sun1, Haiyan Xiong1, Guocheng Jiang1, Baihe Zhang1, Mengchao $\mathrm{Wu}^{1}$ and Lixin Wei ${ }^{* 1}$

Address: ${ }^{1}$ Tumor Immunology and Gene Therapy Center, Eastern Hepatobiliary Surgery Hospital, the Second Military Medical University, Shanghai, PR China, ${ }^{2}$ Hang Zhou Sanitarium of PLA, Zhejiang, PR China and ${ }^{3}$ Department of Oncology, ChangZheng Hospital, the Second Military Medical University, Shanghai, PR China

Email: Xianling Guo - guoguo1188@gmail.com; Nannan Ma - 2005nan0122@163.com; Jin Wang - jinwang1979@msn.com; Jianrui Song - songjr119@163.com; Xinxin Bu - jesscica123@126.com; Yue Cheng - chengyuextp@126.com; Kai Sun - zhesuk621@126.com; Haiyan Xiong - bearpetrel@ hotmail.com; Guocheng Jiang - jiangguocheng409@yahoo.com.cn; Baihe Zhang - bhz@smmu.edu.cn; Mengchao Wu - wumengchao@yahoo.cn; Lixin Wei* - weilixin@yahoo.com

* Corresponding author †Equal contributors

Published: 18 December 2008

BMC Cancer 2008, 8:375 doi:10.1 I86/147|-2407-8-375
Received: II March 2008

Accepted: 18 December 2008

This article is available from: http://www.biomedcentral.com/147I-2407/8/375

(c) 2008 Guo et al; licensee BioMed Central Ltd.

This is an Open Access article distributed under the terms of the Creative Commons Attribution License (http://creativecommons.org/licenses/by/2.0), which permits unrestricted use, distribution, and reproduction in any medium, provided the original work is properly cited.

\begin{abstract}
Background: Chemoresistance is one of the main obstacles to successful cancer therapy and is frequently associated with Multidrug resistance (MDR). Many different mechanisms have been suggested to explain the development of an MDR phenotype in cancer cells. One of the most studied mechanisms is the overexpression of $\mathrm{P}$-glycoprotein (P-gP), which is a product of the MDRI gene. Tumor cells often acquire the drug-resistance phenotype due to upregulation of the MDRI gene. Overexpression of MDRI gene has often been reported in primary gastric adenocarcinoma.

Methods: This study investigated the role of P38-MAPK signal pathway in vincristine-resistant SGC790I/VCR cells. P-gP and MDRI RNA were detected by Western blot analysis and RT-PCR amplification. Mitgen-activated protein kinases and function of $P$-gp were demonstrated by Western blot and FACS Aria cytometer analysis. Ap-I activity and cell apoptosis were detected by Dual-Luciferase Reporter Assay and annexin V-PI dual staining.

Results: The vincristine-resistant SGC790I/VCR cells with increased expression of the multidrugresistance I $(M D R I)$ gene were resistant to P-gP-related drug and P-gp-unrelated drugs. Constitutive increases of phosphorylated P38-MAPK and AP-I activities were also found in the drug-resistant cells. Inhibition of P38-MAPK by SB202190 reduced activator protein-I (AP-I) activity and MDRI expression levels and increased the sensitivity of SGC790I/VCR cells to chemotherapy.

Conclusion: Activation of the p38-MAPK pathway might be responsible for the modulation of $\mathrm{P}$ glycoprotein-mediated and P-glycoprotein-unmediated multidrug resistance in the SGC790I/VCR cell line.
\end{abstract}




\section{Background}

Multidrug resistance (MDR) is a serious problem in chemotherapy and is one of the main causes of poor outcome following cancer treatment. The MDR phenotype is often related to overexpression of drug-efflux pumps in cancer cells. P-glycoprotein (P-gp), a 170-kDa transmembrane glycoprotein encoded by the MDR1 gene, is one of the best characterized drug efflux pumps [1-3]. Overexpression of P-gp on the surface of tumor cells allows removal of cytotoxic drugs out of the cell in an energy-dependent manner, thereby reducing drug accumulation and increasing multidrug resistance. In addition, inhibition of the Pgp function or inhibition of its expression could prevent the P-gp-mediated MDR phenotype and improve the effectiveness of chemotherapy[4]. However, there is accumulating evidence that P-gp-associated MDR cells develop other pathways instigating chemoresistance to Pgp-unrelated drugs such as cisplatin and 5-FU [5-9].

Expression of P-gp has been reported to be regulated through transcriptional and post-transcriptional mechanisms and by various endogenous and environmental stimuli that evoke stress responses [10]. The transcriptional factor AP-1 has been shown to mediate P-gp expression [11]. Regulation of the AP-1 pathway is highly complex and activation of certain signal pathways seems to stimulate the transcriptional activity of AP-1 [12]. Simultaneous expression of P-gp and activation of several signal pathways has been found in some cancer cells. Moreover, these pathways have been reported to regulate the expression of P-gp in some multidrug-resistant cell lines [13-15], and blocking these pathways with their specific inhibitors has also been found to reduce P-gp expression $[13,16]$. These studies suggest that signal pathways play a positive role in the regulation of P-gp expression

In the present study, we assessed p38-MAPK phosphorylation and AP-1 activity in drug-resistant and drug-sensitive gastric cancer cells. Furthermore, the effect of the p38MAPK inhibitor SB202190 on the MDR1 gene expression and AP-1 activity was also tested.

\section{Methods \\ Cell Culture and reagents}

Drug-sensitive human gastric cancer cell SGC7901 and the corresponding vincristine-resistant cell SGC7901/VCR were kindly provided by the Institute of Digestive Diseases (Fourth Military Medical University). All cells were cultivated in RPMI1640 medium (Gibco) supplemented with $10 \%$ heat-inactivated fetal calf serum in a $\mathrm{CO}_{2}$ incubator. To maintain the drug-resistance phenotype of SGC7901/ VCR cells, vincristine $(1.0 \mu \mathrm{g} / \mathrm{ml})$ was also added to the medium. Cisplatin, 5-fluorouracil (5-FU) and epirubicin were purchased from QILU PHARMA (JiNan, Shandong, China). SB202190 was obtained from TOCRIS (Ballwin,
$\mathrm{MO}, \mathrm{USA})$. The AP-1 luciferase report plasmid and the dominant-negative mutant p38 (DN-p38) plasmid were kind gifts from Dr Chuanshu Huang $[17,18]$.

\section{Cell Viability Assay}

A total of 4,000 SGC7901/VCR and SGC7901 cells were seeded in a 96-well plate. After 24 hours, cells were treated with different concentrations of 5-FU, cisplatin, or epirubicin. After 72 hours, the MTT assay was performed to evaluate cell viability.

\section{Luciferase assay}

Cells were cultured in a twenty four-well plate until they reached $85-90 \%$ confluence. In all, total $0.8-1 \mu \mathrm{g}$ plasmid DNA (DN-p38 plasmid mixed with AP-1 luciferase report plasmid) and $2.5 \mu \mathrm{l}$ LipofectAMINE 2000 (Invitrogen, Carlsbad, CA, USA) mixed together were used to transfect each well in the absence of serum. After 4-6 h, the medium was replaced with $10 \%$ fetal calf serum RPMI1640. Approximately $36 \mathrm{~h}$ after the beginning of the transfection, cells were lysed and Luciferase assays were performed using the Dual Luciferase Reporter Assay System (Promega, WI, USA). A Renilla luciferase plasmid was also cotransfected in each experiment as an internal control for transfection efficiency. The relative luciferase activity reported here is the mean of three replicate experiments.

\section{RT-PCR Amplification}

RNA was extracted from cells using Trizol (Invitrogen, Carlsbad, CA, USA). cDNA was synthesized using MMLV reverse transcriptase(Promega, WI, USA) and $2 \mu \mathrm{g}$ total RNA and oligo $\mathrm{dT}_{18}$-primers. Two-microliter aliquots of CDNA were used for PCR amplification and primers were as follows: sense 5'-AAGCTTAGTACCAAAGAGGCTCTG$3^{\prime}$ and antisense 5'-GGCTAGAAACAATAGTGAAAACAA-3' for MDR-1 [19]; sense 5'-TGACGGGGTCACCCACACTGTGCCCATCTA-3' and antisense 5'-CTAGAAGCATTGCGGTGGACGATGGAGGG-3') for $\beta$-actin [20]. PCR used 32 cycles of 30 seconds at $94^{\circ} \mathrm{C}, 45$ seconds at $58^{\circ} \mathrm{C}$, and 30 seconds at $72^{\circ} \mathrm{C}$ for MDR 1 and $\beta$-actin. PCR products were separated by $2 \%$ agarose gel electrophoresis, and bands were visualized under ultraviolet (UV) radiation after staining with ethidium bromide. Gels were photographed and bands were analyzed by computerized densitometry.

\section{Western-blot analysis}

Protein extracts were prepared using a nuclear extract kit (Active Motif, Carlsbad, CA, USA). Protein samples (30 $\mu \mathrm{g}$ ) were separated by SDS-polyacrylamide gel electrophoresis (PAGE) and transferred to nitrocellulose membranes. Membranes were incubated at $4{ }^{\circ} \mathrm{C}$ overnight with various primary antibodies against P-gp (Sigma, St Louis, MO, USA), $\beta$-actin, and phosphorylated or non-phospho- 
rylated extracellular kinase receptor kinases (ERKs), Jun $\mathrm{N}$-terminal kinases (JNKs) and p38 kinase (Cell Signaling Technology, Beverly, MA, USA). The resulting immunoblots were visualized with horseradish peroxidase-coupled goat anti-rabbit or anti-mouse immunoglobulin using an enhanced chemiluminescence (ECL) substrate system (Amersham Biosciences, Piscataway, NJ, USA).

\section{Apoptosis analysis with annexin V-PI dual staining} Cells $\left(2 \times 10^{5}\right.$ per well) were cultured in six-well plates to $70 \%-80 \%$ confluence. Cells were then treated with the indicated concentrations of chemotherapeutic agents, with or without SB202190 $(10 \mu \mathrm{M})$, for 24 hours. Cells were collected and the annexin V-PI dual-staining assay was performed according to the manufacturer's instructions ((Nanjing Keygen Biotech, China). Collected cells were briefly washed with ice-cold phosphate-buffered saline (PBS) twice and resuspended in $300 \mu \mathrm{l} 1 \times$ binding buffer containing $5 \mu \mathrm{l}$ Annexin V and $5 \mu$ l Propidium iodide (PI) for 30 minutes at room temperature in the dark. After incubation; the cells were analyzed using a FACS Aria cytometer (Becton Dickinson; San Jose, CA).

\section{FACS analysis for MAP-kinase}

Cells were collected and resuspended in 0.5-1 ml PBS and formaldehyde was added to a final concentration of 2$4 \%$. The cells were fixed for 10 minutes at $37^{\circ} \mathrm{C}$ and then chilled on ice for 1 minute. For permeabilization, prechilled cells were centrifuged and resuspended in $90 \%$ icecold methanol. Cells were then incubated for 30 minutes on ice. Permeabilized cells $\left(1 \times 10^{6}\right)$ were mixed with 100 $\mu \mathrm{l} 0.5 \%$ bovine serum albumin (BSA)/PBS containing 2 $\mu \mathrm{g} / \mathrm{ml}$ phospho-ERK, phospho-p38 MAPK, or phosphoJNK-specific antibody and incubated for 1 hour at room temperature. Cells were then washed with $0.1 \%$ BSA/PBS followed by incubation with goat anti-mouse immunoglobulin G (IgG) fluorescein isothiocyanate (FITC)conjugated antibodies $(50 \mu \mathrm{g} / \mathrm{ml}, \mathrm{KPL})$ for 30 minutes at room temperature. Cells were washed again with $0.1 \%$ BSA/PBS, then resuspended in $0.5 \mathrm{ml}$ PBS and analyzed by flow cytometry.

\section{Accumulation and efflux of Rh I 23 was measured by flow cytometry}

The measurement of Rh123 accumulation was performed. Briefly, cells ( $5 \times 10^{5}$ per sample) were incubated with 1 $\mu \mathrm{g} / \mathrm{mL}$ of $\mathrm{Rh} 123$ in the dark at $37^{\circ} \mathrm{C}$ in $5 \% \mathrm{CO}_{2}$ for 120 min. SB202190 was added to cultures at the same time as Rh123. Following Rh123 accumulation, cells were washed twice with ice-cold Hanks' Balanced Salt (HBSS) (without phenol red), placed in HBSS with 10\% fetal bovine serum on ice. The green fluorescence of Rh123 was measured by flow cytometry. For determination of Rh123 efflux, cells were loaded for 120 min with Rh123 in the absence of SB202190, and then the medium was replaced with Rh123-free medium containing SB202190, or the vehicle. Following efflux intervals of $60 \mathrm{~min}$, the medium was removed, and the cells were washed twice with icecold HBSS and prepared for flow cytometry as described earlier.

\section{Statistical analysis}

Values were expressed as means \pm standard deviation (S.D.). Differences were analyzed using the Student's $t$ test. A P-value of $<0.05$ was considered significant.

\section{Results}

SGC790IIVCR cells are more resistant to chemotherapy than SGC790I cells

The human gastric cancer cell line-SGC7901/VCR is a vincristine-resistant cell line that is derived from the vincristine-sensitive parent cell line SGC7901 [21]. To test whether SGC7901/VCR is more resistant to other chemotherapeutic agents than SGC7901, we treated these two kinds of cells with different concentrations of cisplatin, 5FU and epirubicin. MTT assay results and $\mathrm{IC}_{50}$ values showed that SGC7901/VCR cells were more resistant to these chemotherapeutic agents. (Fig. 1A-C, Table 1 [see Additional file 1]). These results also indicated that SGC7901/VCR is a multidrug-resistant cancer cell line, which is resistant to P-gp-related drugs (vincristine and epirubicin) and P-gp-unrelated drugs (cisplatin and 5FU).

\section{Increased expression of MDRI in SGC790I/VCR cells}

Although many different mechanisms have been suggested to explain the development of an MDR phenotype in cancer cells, one of the most extensively studied form of MDR is the P-gp-associated MDR phenotype, and a number of studies have convincingly supported that P-gp expression in tumor cells correlates with poor prognosis of chemotherapy [22]. Meanwhile, vincristine and epirubicin are known as P-glycoprotein substrate and cells resistant to these two drugs often overexpress P-glycoprotein. Therefore, we used Western-blot and RT-PCR analyses to investigate MDR1 gene expression in SGC7901 and SGC7901/VCR cells. As shown in Fig. 1D and 1E, SGC7901/VCR cells have increased expression levels of Pgp protein and MDR1 mRNA than SGC7901. Furthermore, we investigated whether cisplatin or 5-FU could induce MDR1 gene expression in SGC7901 cells; RT-PCR analyses showed that cisplatin or 5-FU treatment could not induce MDR1 gene mRNA expression (data not show). Thus, these results suggested P-gp-related or unrelated mechanism may involved in SGC7901/VCR cells to develop chemoresistance.

\section{Activation of p38-MAPKIAP-I pathway in SGC790 I/VCR cells}

Several studies have suggested that expression of MDR1 is regulated at the transcriptional level by multiple factors that can be activated via the stress-response pathways [23- 
A

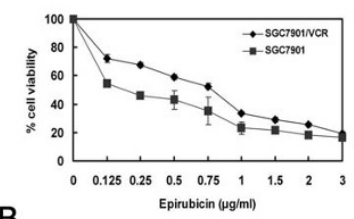

B

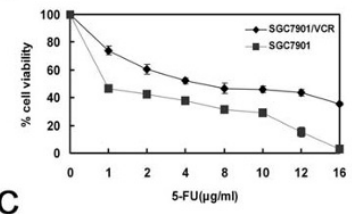

C

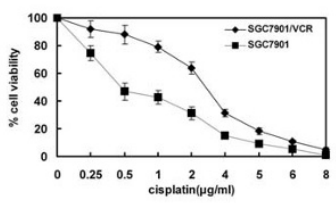

$\mathrm{D}$

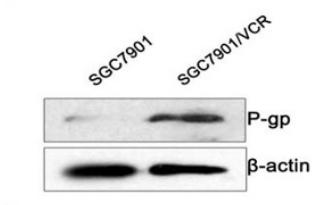

E

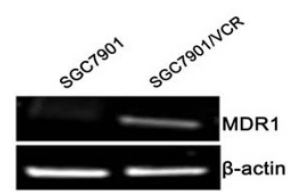

A

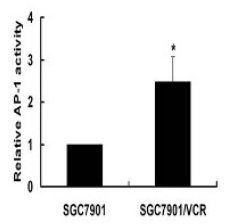

B

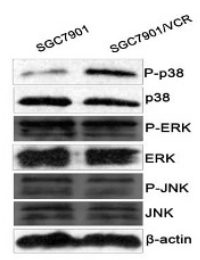

C

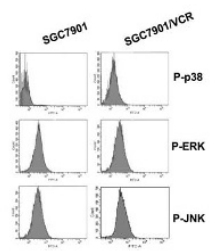

D

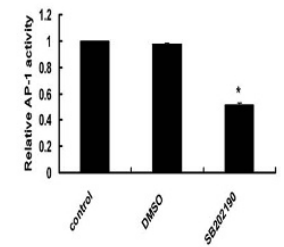

E

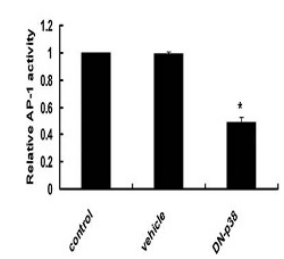

$\mathbf{F}$

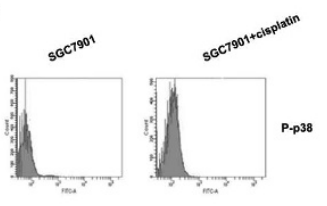

Figure I

SGC790I/VCR cells that overexpress MDRI are more resistant to chemotherapy than SGC790 I cells. (A-C) After treatment with different concentrations of 5-FU, cisplatin or epirubicin for 72 hours, cell viability was determined using the MTT assay. The viability of the untreated cells was taken as $100 \%$. Points, mean of three independent experiments; bars, SD. Significant differences are indicated by asterisks. *, P < 0.05. (D) SGC790I/VCR and SGC790I cells were harvested to prepare cell lysates. The lysates were subjected to SDS-PAGE and blotted with anti-P-gP antibody. (E) RT-PCR assays were performed to detect MDRI mRNA. A representative example of an experiment that was repeated three times is shown.

26]. AP-1 is a well-known mediator of the stress-response pathways, which are composed of heterodimers from the Jun and Fos protein families [27]. Previous report has demonstrated that AP-1 is a transcription factor of MDR1 [11]. We therefore investigated AP-1 activities in SGC7901 and SGC7901/VCR cells using a luciferase reporter assay. Our results clearly showed that AP-1 activity was much greater in SGC7901/VCR cells than in SGC7901 cells (Fig. 2A).

AP-1 is a downstream target of the mitogen-activated protein (MAP) kinase pathway [27], and significant changes of MAP kinase levels in some drug-resistant cells have been reported $[28,29]$. We investigated the signaling pathway that regulates the activation of AP-1 in SGC7901/VCR and SGC7901 cells. Western-blot analysis of MAP kinases revealed that phosphorylation of p38-MAPK, but not ERKs and JNKs, is specifically increased in SGC7901/VCR cells (Fig. 2B). These results were confirmed by FACS anal-

\section{Figure 2}

Activation of p38 MAPK/AP-I pathway in SGC790 I/ VCR cells. (A) SGC790I/VCR and SGC790I cells were transfected with AP-I luciferase reporter plasmids. After 24 hours, the cells were collected and luciferase assays were performed. The luciferase activity results in SGC790 I cells were normalized to I.0. Error bars indicate standard deviations. The values shown represent the means of at least three separate experiments. Significant differences are indicated by asterisks. *, P < 0.05. (B) Levels of phosphorylated and non-phosphroylated MAP kinases (p38-MAPK, ERKs and JNKs) in SGC790I/VCR and SGC790 I cells were detected using Western-blot analyses. A representative example of an experiment that was repeated three times is shown. (C) FACS analysis of P38-MAPK, ERK and JNK phosphorylation. A representative example of an experiment that was repeated three times is shown. (D-E) Analysis of AP-I activity using the luciferase assay in SGC790I/VCR cells treated or untreated with SB202I 90 (I0 $\mu \mathrm{M})$, or cotransfected with the DN-p38 plasmid for 24 hours. The luciferase activity in control samples was normalized to I.0. Error bars indicate standard deviations. The values shown represent the means of at least three separate experiments. Significant differences are indicated by asterisks. *, P < 0.05. (F) SGC790 I cells were incubated with cisplatin $(2 \mu \mathrm{g} / \mathrm{ml})$ for $24 \mathrm{~h}$, and then cells were collected. FACS analysis was used to detect p38MAPK phosphorylation.

ysis: SGC7901/VCR cells showed significant increased phosphorylation of p38-MAPK (Fig. 2C). Luciferase assay results also showed that inhibition of $\mathrm{p} 38-\mathrm{MAPK}$ by SB202190 or after transfection with the DN-p38 plasmid significantly reduced AP-1 activity in SGC7901/VCR cells (Fig. 2D, E). Furthermore, incubation with cisplatin for 24 
$\mathrm{h}$ can also induce p38 phosphorylation in SGC7901 cell s (Fig. 2F). Taken together, these results showed that the p38-MAPK/AP-1 pathway was activated in SGC7901/VCR cells, and contributed to chemoresistance.

\section{Inhibition of p38-MAPK increases sensitivity of SGC790 II} VCR cells to chemotherapy

Our previous data clearly showed that the p38-MAPK/AP1 pathway was activated in SGC7901/VCR cells. Moreover, AP-1 was reported to be involved in MDR1 upregulation [11]. We then investigated the effects of p38-MAPK inhibition on MDR1 expression and function of P-gp. Western-blot analysis showed that inhibition of p38MAPK by SB202190 markedly downregulated P-gp expression in SGC7901/VCR cells. This effect was confirmed by RT-PCR analysis (Fig. 3A-C). To examine the effect of SB202190 on function of P-gp, Rh123 accumulation and efflux studies were chosen. As shown in Figure 3D, Rh123 accumulation and retention in SGC7901/VCR cells were obviously less than that in SGC7901 cells. After treatment with SB202190 $(10 \mu \mathrm{M})$, Rh123 accumulation and retention in SGC7901/VCR cells were increased; however, there was no change in SGC7901 cells(Fig. 3D). Thus, our results clearly showed that inhibition of p38MAPK reduced MDR1 gene expression and function of Pgp in SGC7901/VCR cells.

Upregulation of the MDR1 gene has been reported to be closely related to chemotherapy resistance, and inhibition of the MDR1 gene has been shown to increase the sensitivity of tumor cells to P-gp-related chemotherapeutic agents [30]. Although cisplatin and 5-FU are not the substrates of P-gp, it has been reported that increased expression of c-jun contributed to cisplatin resistance, meanwhile it was also reported that 5-FU can induce c-jun phosphorylation and activate both AP-1-specific transcription and DNA binding $[31,32]$. We therefore tested whether inhibition of p38-MAPK could restore the chemotherapeutic sensitivity of drug-resistant tumor cells to Pgp-related drug and P-gp-unrelated drugs. SGC7901/VCR cells were treated with 5-FU, cisplatin and eprubicin for 24 hours, with or without 2-hour pretreatment with SB202190 $(10 \mu \mathrm{M})$. The morphology of cells was observed, and photographs were taken under the microscope. Annexin-V/PI staining analysis was performed to detect cell apoptosis. As shown in Fig. 4A, cells treated with SB202190, but not control cells (not treated with SB202190), showed significantly increased levels of cell death and exhibited typical morphologic features of apoptotic cell death, including cytoplasmic condensation, nuclear fragmentation and membrane blebbing. These results were confirmed by Annexin-V/PI staining analysis (Fig. 4B): cells treated with SB202190 showed significantly increased levels of apoptosis. Taken together, these
A

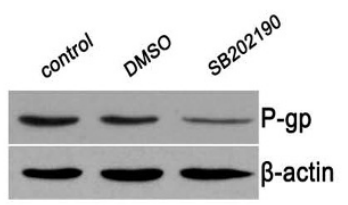

B

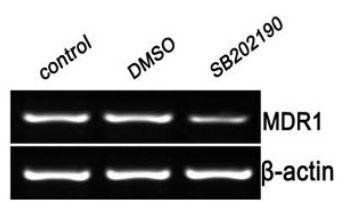

C

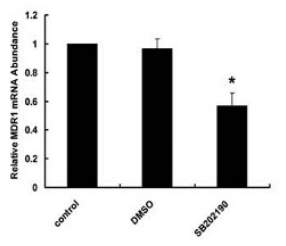

D

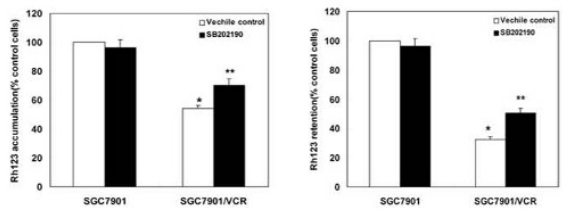

Figure 3

Inhibition of p38-MAPK impairs MDRI expression and function of P-gp in SGC790I/VCR cells. SGC790I/ VCR cells were treated with DMSO or SB202I90 (I0 $\mu \mathrm{M})$.

(A) Protein levels of P-gp were detected by Western-blot analysis. A representative example of an experiment that was repeated three times is shown. (B) SGC790I/VCR cells were treated with DMSO and SB202190. Expression of MDRI mRNA was assessed by RT-PCR. $\beta$-actin mRNA levels were measured as positive internal controls. (C) The MDRI mRNA expression levels were normalized to those of $\beta$-actin and are the means \pm SD of at least three independent experiments. Significant differences are indicated by asterisks. *, P $<0.05$. (D)Effects of SB202 I 90 on Rh 123 accumulation (left) and retention (right) in SGC790I and SGC790I/VCR cells. (left) Cells treated with SB202190 (I0 $\mu$ M) or vehicle control (0.1\% DMSO). RhI23 (I $\mu \mathrm{g} / \mathrm{mL})$ was added, and the cells were incubated for $120 \mathrm{~min}$. (right) Cells were incubated with RhI23 for 120 min, washed, and resuspended in medium with SB202190 (10 $\mu$ M)or vehicle control $(0.1 \%$ DMSO) for 120 min. Rh 123 fluorescence was measured using FAC scan. Means \pm SD from three independent experiments. $* \mathrm{P}<0.05$ vs SGC790I cells. $* * \mathrm{P}<0.05$ vs vehicle control. 
A

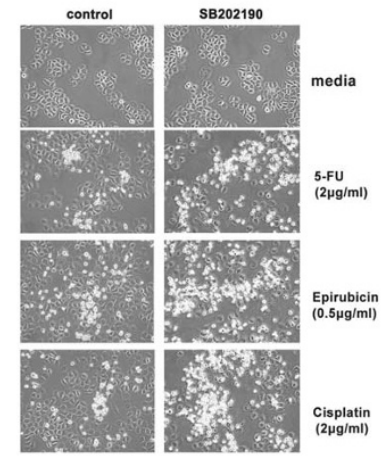

B

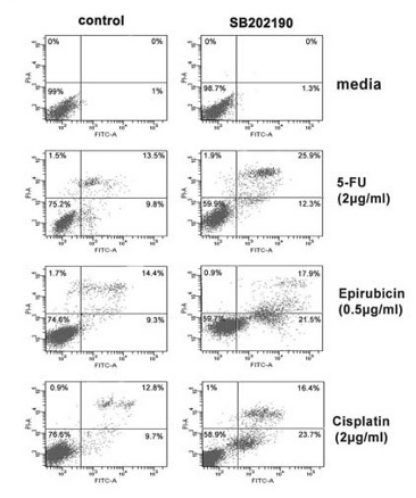

\section{Figure 4}

Inhibition of p38 MAPK increases SGC790I/VCR to chemotherapy. SGC790I/VCR cells were treated with indicated concentrations of cisplatin, 5-FU or epirubicin, with or without SB202190 (10 $\mu$ M), for 24 hours. (A) The morphology of cells was observed, and photographs were taken under the microscope. (B) Flow cytometry analysis was performed after staining with Annexin V/PI. Compared with the control cells (without SB202190), there were significantly more apoptotic cells in the SB230920 treatment group. A representative example of an experiment that was repeated three times is shown.

results indicate that inhibition of $\mathrm{p} 38$-MAPK increases the sensitivity of SGC7901/VCR cells to chemotherapy

\section{Discussion}

Multidrug resistance (MDR) is a phenomenon by which tumor cells develop cross-resistance to a range of structurally and functionally unrelated drugs [33]. MDR is one of the main obstacles to successful cancer therapy [34]. Many different mechanisms have been suggested to explain the development of a MDR phenotype in cancer cells, one of the extensively studied form of these mechanisms is overexpression of several energy dependent drug efflux pumps that belong to the ATP-binding cassette family of transporters, such as the P-glycoprotein (P-gp) and the MDRassociated proteins (MRPs) [33]. P-gp is a product of the MDR1 gene. Overexpression of MDR1 has often been reported in primary gastric adenocarcinoma [35,36]. However, there are some reports showing that P-gp-associated MDR cells develop other mechanisms to acquire chemoresistance to P-gp-unrelated drugs [5-9]. In this study, we found that constitutive overexpression of the MDR1 gene in drug-resistant human gastric cancer SGC7901/VCR cells is dependent on phosphorylation of p38 and the activity of AP-1. Inhibition of p38-MAPK could restore the sensitivity of these cells to P-gp-related drug and P-gp-unrelated drugs

Cultured tumor cells, when selected for resistance to an anti-neoplastic agent, often acquire cross-resistance to others. In this study, we showed that vincristine-rsistant SGC7901/VCR is a multidrug-resistant cancer cell line, which was resistant to P-gp-related drug (eprubicin) and P-gp-unrelated drugs (5-FU and cisplatin). Vincristine and epirubicin are known substrates of P-glycoprotein, and it is now increasingly evident that P-gp-associated MDR cells were conferred a cross-resistance to P-gp-unrelated drugs $[8,9]$. We then examined and compared the levels of MDR1 gene expression in SGC7901/VCR and SGC7901 cells, and showed SGC7901/VCR cells have increased expression levels of P-gp protein and MDR1 mRNA than SGC7901. But cisplatin or 5-FU treatment could not induce MDR1 gene expression in SGC7901 cells. Taken together, these results suggested SGC7901/VCR cells may develop P-gp-related or unrelated mechanism to acquire chemoresistance. Thus, P-gp-associated MDR cell lineSGC7901/VCR has ability to crossresist against P-gprelated drug (eprubicin) and P-gp-unrelated drugs (5-FU and cisplatin). Our results was in agreement with previous findings that the P-gp-prominent MDR cell was crossresistant to 5-FU and cisplatin[37].

It has previously been reported that the human MDR1 promoter contains an AP-1-binding site [38], and increased AP-1 binding [39] has been observed in several multidrug-resistant cell lines whereas reduced AP-1 binding has been associated with increased drug sensitivity in others $[11,40]$. In this study, we observed increased AP-1 activity in SGC7901/VCR cells compared with the drugsensitive parental SGC7901 cells. This result indicates that increased activity of AP-1 is correlated with increased drug resistance in SGC7901/VCR cells.

Recently, increasing evidence indicates that anticancer drugs activate many signal pathways, some of which are connected to the development of drug resistance of tumor cells [41]. The MAP kinase pathway is an important signal-transduction pathway activated by many different stimuli. Previous reports have shown that modulators of the MAP kinase pathway can affect drug transport activity of P-gp in certain multidrug-resistant cell lines $[42,43]$. We investigated the role of the MAP kinase signal pathway in drug-resistant and drug-sensitive cell lines. As shown in Fig. 3B and 3C, phosphorylation of p38 was increased in SGC7901/VCR cells, but there were no differences in phosphorylation of JNKs and ERKs between drug-resistant and drug-sensitive cell lines. Meanwhile, AP-1 activity was significant attenuated by SB202190 or after cotransfection with the DN-p38 plasmid. We also observed that inhibition of p38 by SB202190 markedly decreased levels of P-gp, MDR1 mRNA and function of P-gp. Moreover, the function of P-gp can also be repressed by SB202190 (Fig. 3D) in SGC7901/VCR cells. Furthermore, incubation with cisplatin for $24 \mathrm{~h}$ can also induce p38 phosphorylation in SGC7901 cells; this result is supported by previous report that p38 MAPK was preferentially activated by cis- 
platin in several cell lines [44]. Thus, these results suggest that the p38-MAPK/AP-1 signal pathway is involved in regulation of the MDR1 gene in SGC7901/VCR cells, and may contribute to chemoresistantce. Our results were in line with previous report that the specific p38-MAPK inhibitor SB203580 blocked both c-fos and c-jun expression in response to UV irradiation and anisomycin [45]. Although p38-MAPK does not phosphorylate or activate c-Jun, several lines of evidence however, support the idea that p38 can contribute to AP-1 activity. p38 can contribute to $\mathrm{c}$-jun gene induction mediated by the AP-1 binding site in the c-jun promoter. In addition to the AP-1 site, the c-jun gene can be regulated by MEF2 family of transcription factors (consisting of MEF2 A-D) [46]. The MEF2 site is critical for induction of the c-jun promoter by LPS in macrophages, and that this induction requires functional p38 and transcription factor MEF2C. Furthermore, MEF2C was shown to be directly phosphorylated and activated by p38 [47]. Thus, p38 can potentially regulate c-Jun transcriptional activity by regulating transcription factors that bind to the AP-1 site as well as the MEF2 site.

It has been previously reported in other cell lines that p38MAPK does not affect P-gp and MDR1 mRNA expression $[48,49]$. In this study, we demonstrated that inhibition of p38-MAPK by SB202190 significantly attenuated the activity of AP-1 and MDR1 gene expression. As AP- 1 is the important transcription factor for MDR1 gene expression, we suggest that SB202190 inhibited MDR1 gene expression by reducing the activity of transcription factor AP-1. Thus, the effect of p38-MAPK on MDR1 gene expression is cell type dependent.

Previous reports have showed that increased expression of c-Jun contributed to cisplatin resistance, and 5-FU can induce $c$-Jun phosphorylation and activate AP-1-specific transcription [31,32]. Meanwhile, we have demonstrated that the activity of Ap-1 was upregulated in SGC7901/VCR cells and inhibition of p38-MAPK by SB202190 can reduce the activity of AP-1 and inhibit MDR1 gene expression. Therefore, we investigated the effect of SB202190 on the multidrug-resistant phenotype of drug-resistant SGC7901/ VCR cells. As shown in Fig. 6, SB202190 significantly increased the sensitivity of drug-resistant SGC7901/VCR cells to chemotherapeutic agents, which indicates that SB202190 may reverse the multidrug-resistant phenotype in SGC7901/VCR cells. Our results were consistent with previous reports that pharmaceutical inhibition of p38 by SB203580 reversed the multidrug resistance of L1210/VCR cells [42]. It has also been reported that the p38 MAPK pathways play an important role in cellular resistance against photodynamic therapy with hypericin in HeLa cells [50]. Therefore, it could be suggested from our results that drug resistance in SGC7901/VCR cells is attributed at least in part to the activation of $\mathrm{p} 38-\mathrm{MAPK} / \mathrm{AP}-1$ signal pathway, and downregulation of this pathway appears to confer on MDR cells sensitivity to P-gp-unrelated drugs as well as Pgp-related drug. Several reports have showed that specific inhibitors of signal pathway can reverse P-gp-mediated multidrug resistance $[42,43,51,52]$. Thus, interrupting signal-transduction pathways that mediate the expression of multidrug transporters might be an effective approach to prevent multidrug resistance and increase sensitivity to chemotherapy in human cancers. Taken together, our data indicate that the p38-MAPK signal pathway affects MDR1 gene expression, and provide a possible new mechanism for cross-resistance in drug-resistant human gastric cancer cells. These results further our understanding of the regulatory mechanisms involved in MDR1 gene expression and may provide new strategies for reversal of multidrug resistance in human gastric cancer cells.

\section{Conclusion}

Activation of the p38-MAPK pathway might be responsible for the modulation of P-glycoprotein-mediated multidrug resistance in the SGC7901/VCR cell line.

\section{Abbreviations}

MAPK: mitogen-activated protein kinases; MDR: multidrug resistance; $\mathrm{AP}-1$ : activator protein-1.

\section{Competing interests}

The authors declare that they have no competing interests.

\section{Authors' contributions}

XLG and NNM carried out the molecular genetic studies, participated in the sequence alignment and drafted the manuscript. JW, JRS and XXB carried out the immunoassays. YC participated in the sequence alignment. KS and HYX carried out cellular studies. GCJ and BHZ participated in the design of the study and performed the statistical analysis. MCW and LXW conceived of the study, and participated in its design and coordination. All authors read and approved the final manuscript.

\section{Additional material}

\section{Additional file 1}

Cytotoxicity of different chemotherapeutic drugs in SGC7901 and SGC7901/VCR cell lines expressed as $I C_{50}{ }^{*}$ values obtained by MTT assay. The data provided represent the statistical analysis of the cytotoxicity of different chemotherapeutic drugs in SGC7901 and SGC7901/VCR cell lines expressed as $I C_{50}{ }^{*}$ values, ${ }^{*}$ Each $I C_{50}$ value (lethal dosage required to inhibit $50 \%$ of cell growth) is the average $I C_{50}$ value of three independent MTT assay. Relative resistance is defined as the $\mathrm{IC}_{50}$ value of the drug-resistant cells divided by the $I_{50}$ value of the parent SGC7901 cells (concentrations are expressed in $\mu \mathrm{g} / \mathrm{ml}$ ).

Click here for file

[http://www.biomedcentral.com/content/supplementary/14712407-8-375-S1.doc] 


\section{Acknowledgements}

This project was supported by the Special Funds for National Natural Science Foundation of China (Grant No: 3070098I,3080 I 347,30870974), the Commission of Science and Technology of Shanghai Municipality (Grant No:045407047, 08XD I 4003), National Key Sci-Tech Special Project of China (Grant No: 2008ZX10002-019, 2008ZX10002-025) and the "Tenth Five-year Plan" of PLA (Grant No: 04A-8).

\section{References}

I. Gottesman MM, Fojo T, Bates SE: Multidrug resistance in cancer: role of ATP-dependent transporters. Nat Rev Cancer 2002, 2(1):48-58.

2. Endicott JA, Ling V: The biochemistry of P-glycoprotein-mediated multidrug resistance. Annu Rev Biochem 1989, 58:|37-I7|.

3. Ambudkar SV, Dey S, Hrycyna CA, Ramachandra M, Pastan I, Gottesman MM: Biochemical, cellular, and pharmacological aspects of the multidrug transporter. Annu Rev Pharmacol Toxicol 1999. 39:36I-398.

4. Hait WN, Yang JM: Clinical management of recurrent breast cancer: development of multidrug resistance (MDR) and strategies to circumvent it. Semin Oncol 2005, 32(6 Suppl 7):SI6-2I.

5. Mickisch G, Fajta S, Bier H, Tschada R, Alken P: Cross-resistance patterns related to glutathione metabolism in primary human renal cell carcinoma. Urol Res I99|, 19(2):99-103.

6. Chao CC: Cross-resistance to cis-diamminedichloroplatinum(II) of a multidrug-resistant lymphoma cell line associated with decreased drug accumulation and enhanced DNA repair. Eur J Pharmacol 1996, 305(I-3):2 I3-222.

7. Satta T, Isobe K, Yamauchi M, Nakashima I, Takagi H: Expression of MDRI and glutathione $S$ transferase-pi genes and chemosensitivities in human gastrointestinal cancer. Cancer 1992, 69(4):94I-946.

8. Kang CD, Ahn BK, Jeong CS, Kim KW, Lee HJ, Yoo SD, Chung BS, Kim SH: Downregulation of JNK/SAPK activity is associated with the cross-resistance to P-glycoprotein-unrelated drugs in multidrug-resistant FM3A/M cells overexpressing P-glycoprotein. Exp Cell Res 2000, 256(I):300-307.

9. Riganti C, Miraglia E, Viarisio D, Costamagna C, Pescarmona G, Ghigo $D$, Bosia A: Nitric oxide reverts the resistance to doxorubicin in human colon cancer cells by inhibiting the drug efflux. Cancer Res 2005, 65(2):516-525.

10. Sukhai M, Piquette-Miller M: Regulation of the multidrug resistance genes by stress signals. J Pharm Pharm Sci 2000, 3(2):268-280.

II. Daschner PJ, Ciolino HP, Plouzek CA, Yeh GC: Increased AP-I activity in drug resistant human breast cancer MCF-7 cells. Breast Cancer Res Treat 1999, 53(3):229-240.

12. Whitmarsh AJ, Davis RJ: Transcription factor AP-I regulation by mitogen-activated protein kinase signal transduction pathways. J Mol Med I996, 74( I0):589-607.

13. Han Z, Hong L, Han Y, Wu K, Han S, Shen H, Li C, Yao L, Qiao T, Fan D: Phospho Akt mediates multidrug resistance of gastric cancer cells through regulation of $\mathbf{P}$-gp, $\mathrm{Bcl}-2$ and $\mathrm{Bax}$. J Exp Clin Cancer Res 2007, 26(2):26I-268.

14. Chen B, Jin F, Lu P, Lu XL, Wang PP, Liu YP, Yao F, Wang SB: Effect of mitogen-activated protein kinase signal transduction pathway on multidrug resistance induced by vincristine in gastric cancer cell line MGC803. World J Gastroenterol 2004, I 0(6):795-799.

15. Kuo MT, Liu Z, Wei Y, Lin-Lee YC, Tatebe S, Mills GB, Unate H: Induction of human MDRI gene expression by 2acetylaminofluorene is mediated by effectors of the phosphoinositide 3-kinase pathway that activate NF-kappaB signaling. Oncogene 2002, 21 (13): 1945-1954.

16. Nwaozuzu OM, Sellers LA, Barrand MA: Signalling pathways influencing basal and $H(2) O(2)$-induced P-glycoprotein expression in endothelial cells derived from the blood-brain barrier. J Neurochem 2003, 87(4): I043-105I.

17. Li J, Tang MS, Liu B, Shi X, Huang C: A critical role of PI-3K/Akt/ JNKs pathway in benzo[a]pyrene diol-epoxide (B [a]PDE)induced AP-I transactivation in mouse epidermal Cl4 I cells. Oncogene 2004, 23(22):3932-3944.
18. Huang C, Ma WY, Maxiner A, Sun Y, Dong Z: p38 kinase mediates UV-induced phosphorylation of $\mathrm{p} 53$ protein at serine 389 . J Biol Chem 1999, 274( I 8): I2229-1 2235.

19. Mantwill K, Kohler-Vargas N, Bernshausen A, Bieler A, Lage H, Kaszubiak A, Surowiak P, Dravits T, Treiber U, Hartung R, et al.: Inhibition of the multidrug-resistant phenotype by targeting YB-I with a conditionally oncolytic adenovirus: implications for combinatorial treatment regimen with chemotherapeutic agents. Cancer Res 2006, 66( I 4):7195-7202.

20. Davies MP, O'Neill PA, Innes H, Sibson DR, Prime W, Holcombe C, Foster CS: Correlation of mRNA for oestrogen receptor beta splice variants ERbetal, ERbeta2/ERbetacx and ERbeta5 with outcome in endocrine-treated breast cancer. $J$ Mol Endocrinol 2004, 33(3):773-782.

21. Zhao Y, You H, Liu F, An H, Shi Y, Yu Q, Fan D: Differentially expressed gene profiles between multidrug resistant gastric adenocarcinoma cells and their parental cells. Cancer Lett 2002, I85(2):2II-2I8.

22. Ling V: Multidrug resistance: molecular mechanisms and clinical relevance. Cancer Chemother Pharmacol 1997, 40(Suppl):S3-8.

23. Ohga T, Koike K, Ono M, Makino Y, Itagaki $Y$, Tanimoto M, Kuwano $M$, Kohno K: Role of the human $Y$ box-binding protein YB-I in cellular sensitivity to the DNA-damaging agents cisplatin, mitomycin C, and ultraviolet light. Cancer Res 1996, 56( I 8):4224-4228.

24. Cornwell MM, Smith DE: SPI activates the MDRI promoter through one of two distinct G-rich regions that modulate promoter activity. J Biol Chem 1993, 268(26):19505-195II.

25. Chin KV, Ueda K, Pastan I, Gottesman MM: Modulation of activity of the promoter of the human MDRI gene by Ras and p53. Science 1992, 255(5043):459-462.

26. Glazer RI, Rohlff C: Transcriptional regulation of multidrug resistance in breast cancer. Breast Cancer Res Treat 1994, 3 I (23):263-27I.

27. Eferl R, Wagner EF: AP-I: a double-edged sword in tumorigenesis. Nat Rev Cancer 2003, 3(I I):859-868.

28. Hayakawa J, Depatie C, Ohmichi M, Mercola D: The activation of c-Jun NH2-terminal kinase (JNK) by DNA-damaging agents serves to promote drug resistance via activating transcription factor 2 (ATF2)-dependent enhanced DNA repair. J Biol Chem 2003, 278(23):20582-20592.

29. Wu Y, Hiwasa $T$, Isogai $E$, Sonoda $T$, Kita $K$, Chen $Z$, Sugaya $S$, Yamamori H, Tanzawa H, Suzuki N: Activation of MAP kinases by 5-fluorouracil in a 5-fluorouracil-resistant variant human cell line derived from a KT breast cancer cell line. Int J Oncol 1998 , 13(6): $124 \mid-1245$

30. Mistry P, Stewart AJ, Dangerfield W, Okiji S, Liddle C, Bootle D, Plumb JA, Templeton D, Charlton P: In vitro and in vivo reversal of P-glycoprotein-mediated multidrug resistance by a novel potent modulator, XR9576. Cancer Res 200I, 6I(2):749-758.

3I. Pan B, Yao KS, Monia BP, Dean NM, McKay RA, Hamilton TC, O'Dwyer PJ: Reversal of cisplatin resistance in human ovarian cancer cell lines by a c-jun antisense oligodeoxynucleotide (ISIS 10582): evidence for the role of transcription factor overexpression in determining resistant phenotype. Biochem Pharmacol 2002, 63(9): 1699-1707.

32. Wendling J, Marchand A, Mauviel A, Verrecchia F: 5-fluorouracil blocks transforming growth factor-beta-induced alpha 2 type I collagen gene (COLIA2) expression in human fibroblasts via c-Jun NH2-terminal kinase/activator protein-I activation. Mol Pharmacol 2003, 64(3):707-7।3.

33. Gottesman MM, Fojo T, Bates SE: Multidrug resistance in cancer: role of ATP-dependent transporters. Nat Rev Cancer 2002, 2(I):48-58.

34. Simon SM, Schindler M: Cell biological mechanisms of multidrug resistance in tumors. Proc Natl Acad Sci USA 1994, 9I(9):3497-3504.

35. Choi JH, Lim HY, Joo HJ, Kim HS, Yi JW, Kim HC, Cho YK, Kim MW, Lee $\mathrm{KB}$ : Expression of multidrug resistance-associated protein I, P-glycoprotein, and thymidylate synthase in gastric cancer patients treated with 5-fluorouracil and doxorubicin-based adjuvant chemotherapy after curative resection. $\mathrm{Br} J$ Cancer 2002, 86( (10): I578- 1585.

36. Lacueva FJ, Teruel A, Calpena R, Medrano J, Mayol MJ, Perez-Vazquez MT, Rufete C, Camarasa MV, Ferragut JA: Detection of P-glycoprotein in frozen and paraffin-embedded gastric adenocarci- 
noma tissues using a panel of monoclonal antibodies. Histopathology 1998, 32(4):328-334.

37. Li L, Jiang AC, Dong $\mathrm{P}$, Wan $Y, Y u Z W$ : The characteristics of Hep-2 cell with multiple drug resistance induced by Taxol. Otolaryngol Head Neck Surg 2007, I 37(4):659-664.

38. Ueda K, Pastan I, Gottesman MM: Isolation and sequence of the promoter region of the human multidrug-resistance (P-glycoprotein) gene. J Biol Chem 1987, 262(36): I7432-I7436.

39. Chen TK, Smith LM, Gebhardt DK, Birrer MJ, Brown PH: Activation and inhibition of the AP-I complex in human breast cancer cells. Mol Carcinog 1996, I 5(3):215-226.

40. Rohlff C, Safa B, Rahman A, Cho-Chung YS, Klecker RW, Glazer RI: Reversal of resistance to adriamycin by 8-chloro-cyclic AMP in adriamycin-resistant HL-60 leukemia cells is associated with reduction of type I cyclic AMP-dependent protein kinase and cyclic AMP response element-binding protein DNA-binding activities. Mol Pharmacol 1993, 43(3):372-379.

4I. Johnstone RW, Ruefli AA, Lowe SW: Apoptosis: a link between cancer genetics and chemotherapy. Cell 2002, I 08(2): I53-I64.

42. Barancik M, Bohacova V, Kvackajova J, Hudecova S, Krizanova O Breier A: SB203580, a specific inhibitor of p38-MAPK pathway, is a new reversal agent of P-glycoprotein-mediated multidrug resistance. Eur J Pharm Sci 200I, I 4(I ):29-36.

43. Kisucka J, Barancik M, Bohacova $V$, Breier A: Reversal effect of specific inhibitors of extracellular-signal regulated protein kinase pathway on P-glycoprotein mediated vincristine resistance of LI 210 cells. Gen Physiol Biophys 200 I, 20(4):439-444.

44. Losa JH, Parada Cobo C, Viniegra JG, Sanchez-Arevalo Lobo V] Ramon y Cajal S, Sanchez-Prieto R: Role of the p38 MAPK pathway in cisplatin-based therapy. Oncogene 2003 , 22(26):3998-4006.

45. Hazzalin CA, Cano E, Cuenda A, Barratt MJ, Cohen P, Mahadevan LC: P38/RK is essential for stress-induced nuclear responses: JNK/SAPKs and c-Jun/ATF-2 phosphorylation are insufficient. Curr Biol 1996, 6(8): 1028-1031.

46. Han TH, Prywes R: Regulatory role of MEF2D in serum induction of the c-jun promoter. Mol Cell Biol 1995, I 5(6):2907-29I5.

47. Han J, Jiang Y, Li Z, Kravchenko VV, Ulevitch RJ: Activation of the transcription factor MEF2C by the MAP kinase p38 in inflammation. Nature 1997, 386(6622):296-299.

48. Katayama K, Yoshioka S, Tsukahara S, Mitsuhashi J, Sugimoto Y: Inhibition of the mitogen-activated protein kinase pathway results in the down-regulation of P-glycoprotein. Mol Cancer Ther 2007, 6(7):2092-2102.

49. Osborn MT, Berry A, Ruberu MS, Ning B, Bell LM, Chambers TC: Phorbol ester induced MDRI expression in $K 562$ cells occurs independently of mitogen-activated protein kinase signaling pathways. Oncogene 1999, I8(42):5756-5764.

50. Assefa Z, Vantieghem A, Declercq W, Vandenabeele P, Vandenheede JR, Merlevede W, de Witte P, Agostinis P: The activation of the cJun $\mathbf{N}$-terminal kinase and p38 mitogen-activated protein kinase signaling pathways protects HeLa cells from apoptosis following photodynamic therapy with hypericin. J Biol Chem 1999, 274(1 3):8788-8796.

5I. Yang JM, Vassil A, Hait WN: Involvement of phosphatidylinositol-3-kinase in membrane ruffling induced by $\mathbf{P}$-glycoprotein substrates in multidrug-resistant carcinoma cells. Biochem Pharmacol 2002, 63(5):959-966.

52. Barancik M, Bohacova V, Sedlak J, Sulova Z, Breier A: LY294002, a specific inhibitor of PI3K/Akt kinase pathway, antagonizes $P$. glycoprotein-mediated multidrug resistance. Eur J Pharm Sci 2006, 29(5):426-434.

\section{Pre-publication history}

The pre-publication history for this paper can be accessed here:

http://www.biomedcentral.com/1471-2407/8/375/pre pub
Publish with Biomed Central and every scientist can read your work free of charge

"BioMed Central will be the most significant development for disseminating the results of biomedical research in our lifetime. "

Sir Paul Nurse, Cancer Research UK

Your research papers will be:

- available free of charge to the entire biomedical community

- peer reviewed and published immediately upon acceptance

- cited in PubMed and archived on PubMed Central

- yours - you keep the copyright

Submit your manuscript here:

http://www.biomedcentral.com/info/publishing_adv.asp
BioMedcentral 